\title{
Longitudinal studies on the development of diabetes in individual Macaca nigra
}

\author{
C.F. Howard, Jr. \\ Oregon Regional Primate Research Center, 505 N. W. 185th Avenue, Beaverton, Oregon, USA
}

\begin{abstract}
Summary. Development of spontaneous diabetes has been monitored in individual Macaca nigra. In this study, pancreatic biopsies were taken, islets were assessed morphologically, and results were related to the metabolic/clinical status. A biopsy or autopsy sample was obtained 4 to 10 years later, and the islet morphological state was again related to the metabol$\mathrm{ic} /$ clinical status. Metabolic deterioration was correlated to the islet lesion, in which there was gradual loss of islet secretory cells and concurrent amyloid deposition. As nondiabetic monkeys with 0 to $3 \%$ islet amyloid progressed up to 20 to $40 \%$ amyloid, the insulin secretion and glucose clearance were
\end{abstract}

both decreased $(p \leqslant 0.01)$, and the glucose and glucagon levels increased $(p=0.05)$. Impaired monkeys progressed to overt diabetes when islet amyloid exceeded 50 to $60 \%$. Diabetic monkeys developed hyperglycaemia, along with impaired insulin secretion and glucose clearance $(p<0.01)$. Loss of islet cells results in metabolic deterioration. The lesion precedes development of overt diabetes in Macaca nigra.

Key words: Amyloid, islet lesion, hyperglycaemia, intravenous glucose tolerance tests, morphometry, monkeys.
Spontaneous diabetes in Celebes black macaques $(\mathrm{Ma}$ caca nigra) is linked to a lesion in the islets of Langerhans in which there is deterioration of secretory cells and deposition of amyloid [1]. The islet lesion in monkeys is similar to one observed in man for over 80 years [2]. When investigators examined human necropsy pancreatic tissue for the presence of islet amyloid and then retrospectively established the clinical status, at least $40 \%$ of the diabetic patients over age 50 were found to have islet amyloid [3-7]. Whether the islet lesion precedes the diabetes or the diabetes contributes to the lesion has not been established experimentally in man. However, Macaca nigra can be used to gain information that is probably relevant to the human situation.

In this study, monkeys were classified as nondiabetic (ND) or diabetic (D) [8]. Those intermediate in severity were classified as borderline diabetic (BD). As more information accumulated, it became possible to identify monkeys in which there were minimal glycaemic abnormalities and classify them as hormonally impaired (HI) $[9,10]$. These classifications were based upon increasing fasting glucose and glucagon concentrations, as well as decreasing glucose clearance and insulin secretion. Increasing amounts of islet amyloid and concurrent cell deterioration were associated with these metabolic/ clinical states $[1,10]$. Since the Macaca nigra colony has now been studied for over a decade it has been possible to longitudinally assess the metabolic and hormonal characteristics of individual monkeys, and to periodically examine the islet morphological state in pancreas sections removed by biopsy or at necropsy. There are now sufficient longitudinal data to conclusively establish the progression of individual monkeys from the $\mathrm{ND}$ to the HI/BD state, and from the HI/BD to the D state. Furthermore, the islet lesion in these Macaca nigra precedes overt diabetes rather than being a secondary development.

\section{Materials and methods}

\section{Monkeys}

Eighteen monkeys were studied. Fourteen of the monkeys were born at the Oregon Regional Primate Research Center (ORPRC). Metabolic data were collected from the time that monkeys were at least 4 years of age; the oldest known age is $>20$ years. Monkeys are sexually mature at about 4 years of age and physically mature at about 10 years of age; adult females weigh 6 to $8 \mathrm{~kg}$ and adult males 8 to $12 \mathrm{~kg}$. The ages of two monkeys obtained as juveniles were estimated from body weight and dentition patterns. Two monkeys were obtained at maturity but of unknown age. These four acquired monkeys have been at the ORPRC for 7 to 10 years, so there has been sufficient time to collect metabolic and islet morphological data. Monkeys were fed Purina 15 Monkey Chow with fruit supplements. 
Table 1. Delineation of metabolic/clinical groups

\begin{tabular}{|c|c|c|c|c|}
\hline & $\begin{array}{l}\text { Nondiabetic } \\
\text { (ND) }\end{array}$ & $\begin{array}{l}\text { Hormonally } \\
\text { impaired/ } \\
\text { borderline } \\
\text { diabetic } \\
\text { (HI/BD) }\end{array}$ & $\begin{array}{l}\text { Diabetic } \\
\text { (D) }\end{array}$ & Units \\
\hline \multicolumn{5}{|c|}{ Intravenous glucose tolerance test (iv-GTT) ${ }^{\mathrm{a}}$} \\
\hline $\mathrm{K}$ & $\begin{array}{r}>2.0 \\
(1)^{\mathrm{b}}\end{array}$ & $\begin{array}{l}1.0-1.9 \\
(2)\end{array}$ & $\begin{array}{r}<1.0 \\
(3)\end{array}$ & $\begin{array}{l}\% \\
\text { clearance/ } \\
\text { min }\end{array}$ \\
\hline$\triangle \mathrm{IRI}$ & $\begin{array}{c}>130 \\
\text { (1) }\end{array}$ & $\begin{array}{l}50-130 \\
(2)\end{array}$ & $\begin{array}{r}<50 \\
(3)\end{array}$ & $\mu \mathrm{U} / \mathrm{ml}$ \\
\hline \multicolumn{5}{|l|}{ Fasting $^{\mathrm{a}}$} \\
\hline Glucose & $\begin{array}{l}50-90 \\
(1)\end{array}$ & $\begin{array}{l}91-115 \\
(2)\end{array}$ & $>\underset{(3)}{115}$ & $\mathrm{mg} / \mathrm{dl}$ \\
\hline Glucagon & $\begin{array}{c}<1000 \\
(1)\end{array}$ & $\begin{array}{l}1000-5000 \\
(2)\end{array}$ & $\begin{array}{l}<1000 \\
\text { (3) }\end{array}$ & $\mathrm{pg} / \mathrm{ml}$ \\
\hline Average & 1.0 & 2.0 & 3.0 & \\
\hline Limits & $1.0-1.25$ & $\begin{array}{l}>1.25 \\
<2.75\end{array}$ & $>2.75$ & \\
\hline
\end{tabular}

a. The $\mathrm{K}$ and IRI values were obtained during intravenous glucose tolerance tests (iv-GTT), whereas glucose and glucagon values were from fasting samples and the zero-time samples of iv-GTT. (K is the percent glucose clearance per min and $\Delta I R I$ is the insulin increment between zero and $15 \mathrm{~min}$ in an iv-GTT. All values are means \pm SEM. ${ }^{b}$ Numbers in parentheses are the values assigned to each measurement according to whether it fell within the $\mathrm{ND}, \mathrm{HI} / \mathrm{BD}$, or D limits

\section{Blood measurements}

Food was withheld from monkeys at $16.00 \mathrm{~h}$, and the fasting blood samples were drawn between 08.00 and $09.30 \mathrm{~h}$ the next day. Serum was assayed for glucose (Beckman glucose oxidase analyzer; Fullerton, CA, USA) and for insulin (Amersham/Searle radioimmunoassay kit; Arlington Hts., IL, USA). Plasma from $4 \mathrm{ml}$ of whole blood containing $10 \mathrm{U}$ of heparin and $0.2 \mathrm{ml}$ of $1 \mathrm{ml} / 1$ benzamidine $\cdot \mathrm{HCl}$ was assayed for glucagon (04A antibody; Health Sciences Center; Dallas, TX, USA); previous work had established the validity of this assay for monitoring immunoreactive glucagon in these monkeys even though absolute values appear elevated [11]. For an intravenous glucose tolerance test (iv-GTT), a fasting sample was drawn and $0.5 \mathrm{~g}$ of glucose per kilogram of body weight was infused within $30 \mathrm{~s}$. A K value ( $\%$ glucose clearance/min) was calculated from samples drawn at 15,30 , and $60 \mathrm{~min}$. The insulin response in an iv-GTT $(\triangle I R I)$ was defined as the insulin concentration at $15 \mathrm{~min}$ minus that in the fasting (time zero) sample $[9,10]$. Computation of the metabolic/clinical status encompassed 3 years from the time of the biopsy ( \pm 1.5 years) and 2 to 3 years before death. Data were available from 3 to 5 iv-GTT and 8 to 12 fasting samples (including zero-time samples from the iv-GTT) on each monkey.

\section{Metabolic/clinical classifications}

An earlier classification system [13] was updated [9-12] and is presented in Table 1. Limits of $\mathrm{K}, \Delta \mathrm{IRI}$, glucose, and glucagon were established for each of the metabolic/clinical stages. The intermediate $\mathrm{HI}$ and BD stages were combined in this study. Measurements within the ND limits were assigned a value of 1 , the HI/BD intermediate measurements were numbered as 2 , and those considered $D$ were given a value of 3 . Since glucagon levels rise in the HI/BD stages and then diminish in the D stage to values comparable to those in the ND stage, assessment of their values as 1 or 3 were judged in context with the other measurements. The ND and D monkeys had at least three of four measurements within that category. When a monkey had average metabolic values of 1.0 to 1.25 , it was considered as ND; for $\mathrm{HI} / \mathrm{BD}$ monkeys, the range was $>1.25$ to $<2.75$; $\mathrm{D}$ monkeys averaged 2.75 to 3.0. A control group included eleven monkeys that did not have islet amyloid and did not have any of the metabolic abnormalities of these categories. Their average age was 11.9 years (range of 8.3 to 14.2 years).

\section{Pancreas sections}

For biopsies, laparotomies were performed, the pancreas was exposed and the tail was blunt-dissected free of membranes; a portion of the tip was ligated and excised [14]. This procedure assured morphological assessment of islets in a consistently identical anatomical area. The interval between obtaining the first pancreas sample by biopsy and obtaining the second sample by biopsy or autopsy averaged $5.3 \pm 0.6$ years (range 3.3 to 10.8 years) for the 13 monkeys progressing from the ND to the HI/BD state, and $4.6 \pm 0.5$ years (range of 3.8 to 6.6 years) for the 7 monkeys progressing from the HI/BD to the D state. Two of these monkeys were followed from the ND to the HI/ BD stages, and subsequently to the $D$ stage. The desired interval between biopsies was 4 to 6 years. Sudden death made some samples available earlier, whereas inability to conduct subsequent surgery because it would have been too traumatic for the monkey caused delays in obtaining a second sample, often until the monkey died. Necropsy tissue was removed from monkeys when they were being killed or, in four instances, within $2 \mathrm{~h}$ after death; the amount of islet amyloid could still be readily measured in the latter cases. Tissue was fixed in buffered neutral formalin, embedded in plastic, and stained with sulfated alcian blue (SAB) or Giemsa. The amount of amyloid was determined by a computerized microphotometry technique (Zonax microscope photometer controller; Zeiss, Inc., Thornwood, NY, USA) [10]. The evaluators of pancreas histology were unaware of the exact metabolic clinical status of each monkey. Reevaluation of the islets by the same observer gave results within $\pm 1 \%$; evaluation of islets by other observers gave values that differed by $<3 \%$ of each other. Changing the threshold limits for assessing the computerized image of the islet amyloid by more than $1 \%$ gave data that was so incongrous that it could be easily rejected [10].

\section{Statistical analysis}

Data were compared with the Student's t-test; a $p$ value of 0.05 or less indicated significance. For examination of the progression of individual monkeys, the Wilcoxon's rank ordering coefficient was used with adjustment for a two-tailed Student's t-test.

\section{Results}

\section{Pancreas pathology}

Representative islets from monkeys of different metabolic states are shown in Figure 1. In Figure $1 \mathrm{~A}$, the islet is normal and no amyloid is present. An islet from a BD monkey with about $20 \%$ cell loss and amyloid replacement is shown in Figure $1 \mathrm{~B}$. Figure $1 \mathrm{C}$ is of an islet from a $\mathrm{D}$ monkey in which there was an average of $65 \%$ amyloid in the islets.

\section{Development of islet lesion and metabolic abnormalities}

$N D$ to $H I / B D$. Average values for the group of ND monkeys progressing to the HI/BD state are given in Table 2. The ND monkeys had minimal or no visible amyloid. The amyloid in HI/BD monkeys was significantly greater than in the ND monkeys $(p<0.01)$. The 


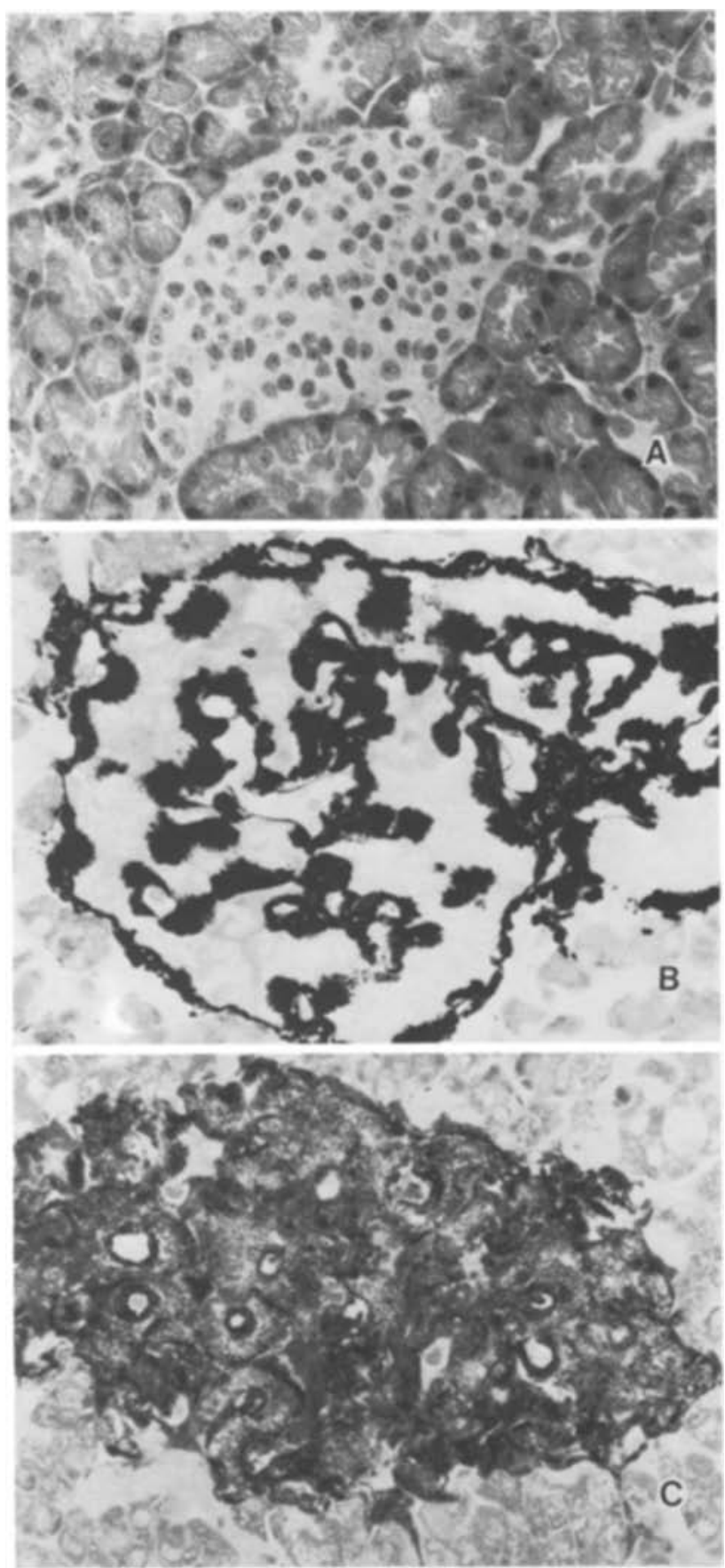

Fig. 1 A-C. Islets of Langerhans from a nondiabetic monkey (A), a borderline diabetic monkey (B), and a diabetic monkey (C), stained with Giemsa stain. Amyloid in borderline diabetic monkeys surrounded the capillaries and generally stained more intensely than in the diabetic monkeys

HI/BD monkeys also had significantly lower $\mathrm{K}$ values and $\triangle I R I$ than did the ND monkeys. The average glucagon and fasting glucose values were not significantly different between the groups.

The data for each parameter in individual monkeys are plotted in Figure 2. The diagram is intended to show how various measurements changed with time. Values at the left were taken when monkeys were considered as
ND. From 3 to 11 years later, when the pancreatic islets were again examined and related to the metabolic status, monkeys had deteriorated to the HI or BD state. Monkeys varied in the rapidity of their progression; no time scale is given. Changes in amyloid, $\mathrm{K}$, and $\Delta \mathrm{IRI}$ were significantly different by either statistical method. Use of nonparametric statistics revealed increases in glucose and glucagon (both at $p=0.05$ ). Glucagon values were not available for one monkey studied before the assay was established.

$H I / B D$ to $D$. The HI/BD progression to the $\mathrm{D}$ state is summarized in Table 3 and Figure 3. Two of the seven monkeys had been monitored in early life and were included in the ND to HI/BD group. The group differences for the HI/BD versus D monkeys were all significant $(p<0.01)$ except for glucagon. Although the D monkeys had metabolite and insulin responses generally in abnormal ranges, variations in the severity and duration of overt diabetes caused differences in the absolute amounts. Hyperglycaemia is obvious at $140 \mathrm{mg} /$ $\mathrm{dl}$, but, as with man, a level of $115 \mathrm{mg} / \mathrm{dl}$ or greater is indicative of impairment [15]. Glucose values in overtly D monkeys appeared to be less because the data from several years were averaged and included values from both the late BD and the D stages. Only one of the seven $D$ monkeys was maintained on insulin therapy. Some of the islet morphological data came from biopsies performed on monkeys in the early stages of diabetes, whereas others came from autopsies performed on monkeys that had been severely diabetic. Use of nonparametric statistics to examine progression of individual monkeys, as plotted in Figure 3, also resulted in statistical significance for glucagon differences $(p<0.05)$. Values at the left were determined when the monkeys were in the HI or BD state at the time of the first biopsy, and the deterioration assessed 4 to 7 years later is plotted at the right.

\section{Discussion}

The lesion in the islets of Langerhans precedes and relates to the gradual development of diabetes mellitus in Macaca nigra. Nondiabetic monkeys have little or no visible evidence of islet deterioration and deposition of amyloid, whereas HI/BD monkeys all have substantial cell loss and amyloid deposition. The HI and BD monkeys were combined as a group for this study because they represented a spectrum of changes between the ND state and overt diabetes. Some of the HI monkeys only had impaired insulin secretion or increased glucagon levels, whereas others, especially BD monkeys, had both hormonal and glycaemic changes.

Glucose clearance becomes measurably impaired in the HI/BD stage. Fasting glucose, the major criterion for diagnosis of diabetes [16], remains within the normal range, although postprandial glucose is slightly elevated 
Table 2. Changes in blood metabolites and hormones, and morphological changes in islets as nondiabetic (ND) monkeys progress to the hormonally impaired/borderline diabetic (HI/BD) state

\begin{tabular}{|c|c|c|c|c|c|c|}
\hline \multirow[t]{2}{*}{ Group } & \multirow{2}{*}{$\begin{array}{l}\text { Pancreas } \\
\text { sample } \\
\text { (years) }^{b}\end{array}$} & \multirow[t]{2}{*}{$\begin{array}{l}\text { Amyloid } \\
(\%)\end{array}$} & \multicolumn{2}{|c|}{$\begin{array}{l}\text { Intravenous glucose tolerance test } \\
\text { (iv-GTT) }^{\mathrm{a}}\end{array}$} & \multicolumn{2}{|l|}{ Fasting ${ }^{a}$} \\
\hline & & & $\begin{array}{l}\mathrm{K} \\
(\% / \mathrm{min})\end{array}$ & $\begin{array}{l}\Delta \mathrm{IRI} \\
(\mu \mathrm{U} / \mathrm{ml})\end{array}$ & $\begin{array}{l}\text { Glucose } \\
(\mathrm{mg} / \mathrm{dl})\end{array}$ & $\begin{array}{l}\text { Glucagon } \\
(\mathrm{pg} / \mathrm{ml})\end{array}$ \\
\hline $\begin{array}{l}\text { Nondiabetic } \\
\text { (ND) }\end{array}$ & $\begin{array}{c}8.9 \pm 0.8 \\
(5.2-13.8)\end{array}$ & $1.4 \pm 0.8$ & $2.6 \pm 0.1$ & $155 \pm 14$ & $72 \pm 3$ & $952 \pm 133$ \\
\hline $\begin{array}{l}\text { Hormonally impaired/ } \\
\text { borderline diabetic } \\
\text { (HI/BD) }\end{array}$ & $\begin{array}{l}14.2 \pm 0.8 \\
(8.7-18.7)\end{array}$ & $31.4 \pm 3.3$ & $1.8 \pm 0.2$ & $116 \pm 16$ & $76 \pm 3$ & $1352 \pm 347$ \\
\hline$p$ value & & $<0.001$ & $<0.01$ & 0.02 & NS & NS \\
\hline
\end{tabular}

a The $\mathrm{K}$ and IRI values were obtained during intravenous glucose tolerance tests (iv-GTT), whereas glucose and glucagon values were from fasting samples and the zero-time samples of iv-GTT. ( $\mathrm{K}$ is the percent glucose clearance per min and $\Delta I R I$ is the insulin increment between zero and $15 \mathrm{~min}$ in an iv-GTT). All values are means \pm SEM. $b$ Values are mean ages \pm SEM in years (range given in parentheses). The first sample was taken by biopsy, whereas the second was either a biopsy or an autopsy sample
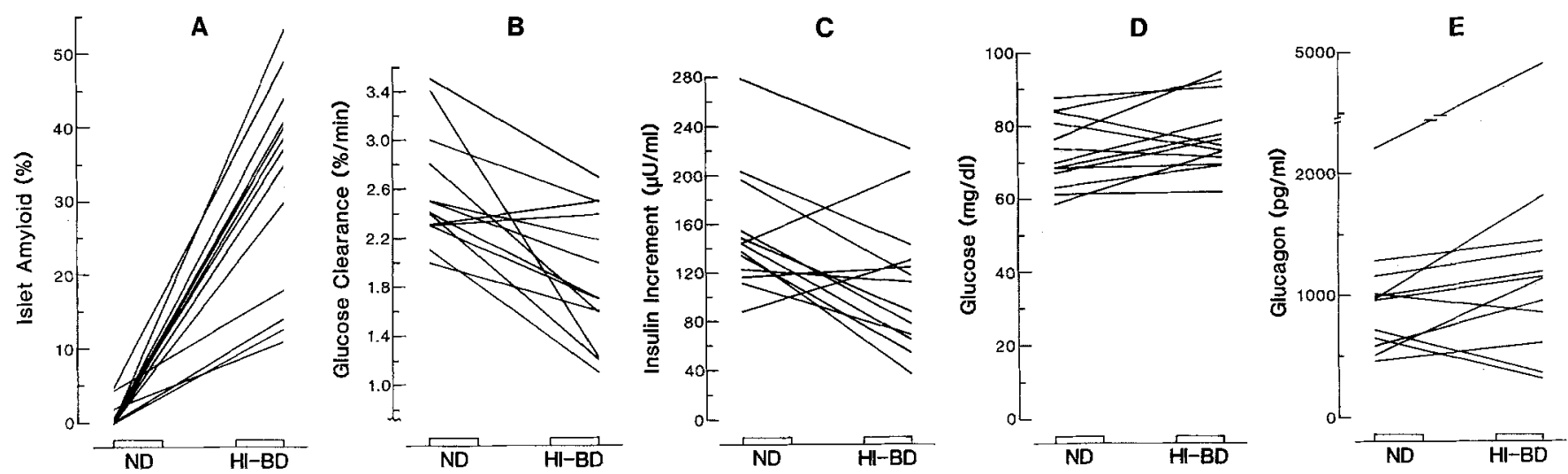

Fig. 2 A-E. Changes in morphological and metabolic parameters indicative of deterioration of individual monkeys toward diabetes. Values for each monkey were graphed at the left when it was classed as nondiabetic (ND) and at the right when it was later classed as hormonally impaired/ borderline diabetic (HI/BD). Individual changes are shown for amyloid (A), glucose clearance (B), acute insulin secretion (C), glucose levels (D), and glucagon concentrations (E). (A)-(C), $p \leqslant 0.01$; (D)-(E), $p=0.05$

Table 3. Changes in blood metabolites and hormones, and morphological changes in islets as hormonally impaired/borderline diabetic (HI/BD) monkeys progress to the diabetic (D) state

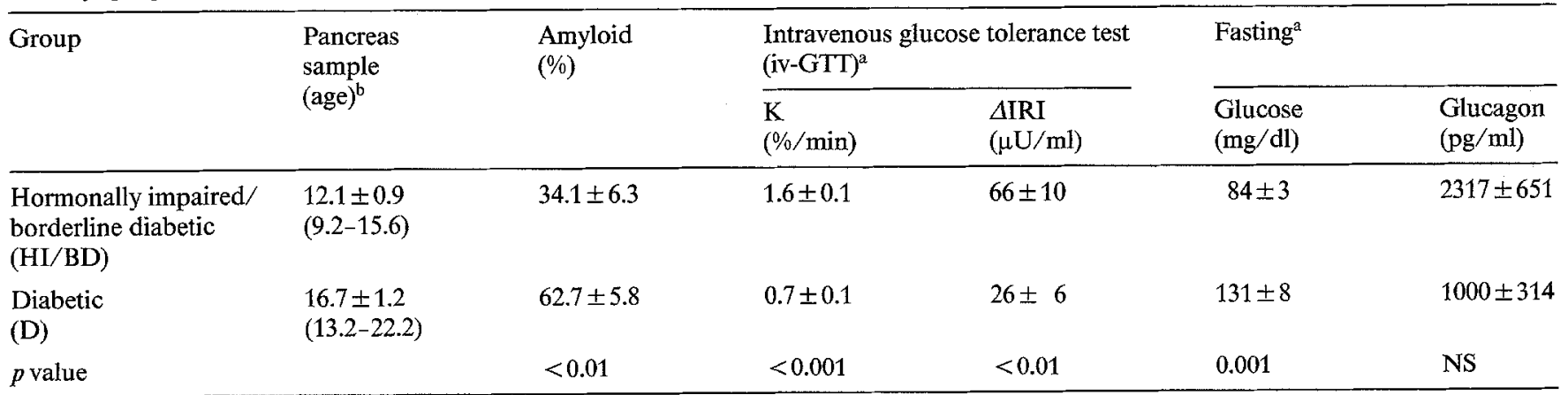

a The $\mathrm{K}$ and IRI values were obtained during intravenous glucose tolerance tests (iv-GTT), whereas glucose and glucagon values were from fasting samples and the zero-time samples of iv-GTT. ( $\mathrm{K}$ is the percent glucose clearance per min and $\triangle$ IRI is the insulin increment between zero and $15 \mathrm{~min}$ in an iv-GTT). All values are means $\pm S E M$. $b$ Values are mean ages $\pm S E M$ in years (range given in parentheses). The first sample was taken by biopsy, whereas the second was either a biopsy or an autopsy sample

in $\mathrm{BD}$ monkeys [12]. Only when individual monkeys are followed can increases in fasting glucose be established. The updated classification system minimized reliance on a single measurement for establishment of the meta- bolic/clinical stage. Since individual monkeys do vary somewhat for different metabolic criteria, the system allowed for some flexibility while still assigning limitations on each category. The changes in the metabolic 

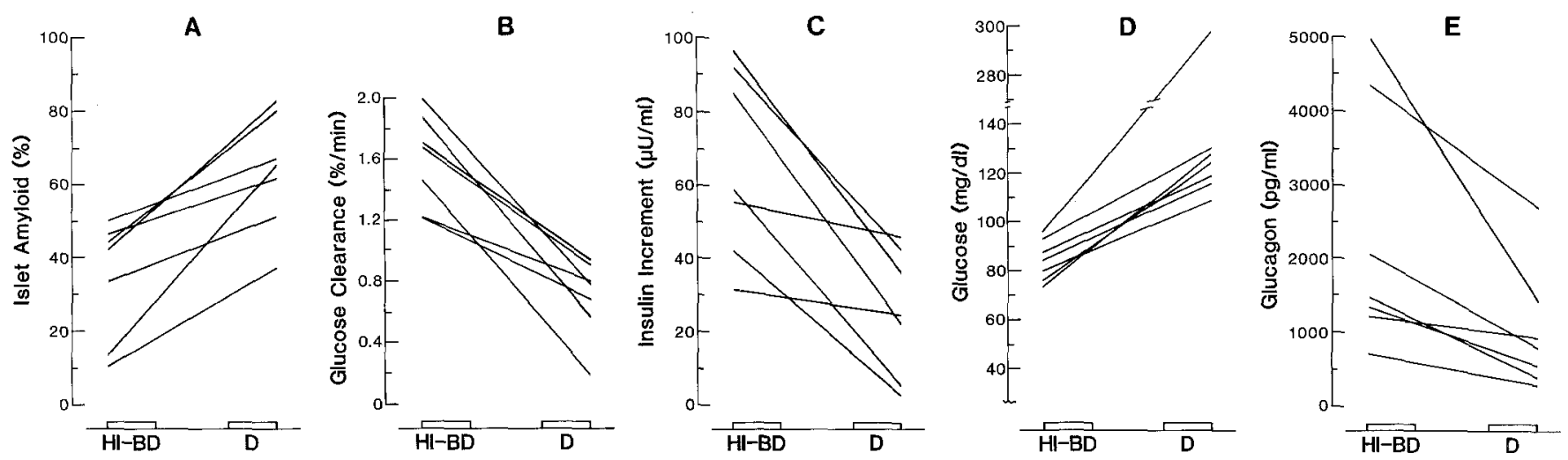

Fig. 3 A-E. Changes in various measurements from the time monkeys were considered hormonally impaired/borderline diabetic (HI/BD), graphed at the left, until they deteriorated to the diabetic state (D), graphed at the right. Parameters included amyloid (A), glucose clearance (B), insulin secretion (C), fasting glucose concentrations (D), and glucagon levels (E). (A)-(D), $p<0.01 ;(\mathrm{E}), p<0.05$

state relative to amyloid are consistent - any loss of islet cells with concurrent amyloid deposition causes significant metabolic deterioration. Control monkeys without islet amyloid did not express the metabolic aberrations described here.

Once amyloid deposition exceeded about $50+\%$, there was sufficient loss of cells such that each monkey was clinically diabetic, i.e. hyperglycaemic at $>115$ $\mathrm{mg} / \mathrm{dl}$. By then, almost all of the hormone levels and responses were abnormal, and the clearance of glucose was noticeably impaired. Presumably, decreased glucagon levels in D monkeys were due to loss in number of functioning alpha cells. It was possible to obtain data on two of the monkeys at all stages, whereas the others were followed only as they deteriorated from one stage to the next. These data also constitute one of the few instances in which a lesion involving amyloid deposition is specifically linked to subtle metabolic changes.

The time for diabetes development varied for each monkey. Some monkeys showed significant changes in just a few years, whereas others required at least a decade. Individual severity relative to the islet lesion also varied; some monkeys showed noticeable metabolic changes with minimal amyloid, whereas others maintained normal levels until the amyloid was extensive. Effects of this lesion appear analogous to the effects seen after much of the pancreas has been surgically removed, i. e. chronic glucose homeostasis may be maintained but the acute responses are impaired [17].

The ability to examine pancreatic islets taken by biopsy at various time intervals provided data beyond that available through examination of autopsy tissue alone. Significant islet changes were detectable only if 3 or more years had elapsed before another pancreas section was examined. Pancreas sections, whether from biopsy or autopsy, were always taken from the tail. A variation of $\pm 10 \%$ in the percentage of amyloid was found among islet within a section; unlike some results reported on man [18], there were rarely instances where a few islets were obliterated by amyloid and others appeared normal. A few pancreas available at autopsy were divided into different anatomical regions.
The percentage of amyloid in islets of the tail, body, and anterior head were similar. The amyloid percentages in the islets of the posterior head were more variable than in other areas. Less amyloid has been found in posterior head islets of diabetic humans [19], but the average percentage in Macaca nigra was only slightly less than that in the tail (unpublished observation). Given that the posterior head comprises only a fraction of the total pancreas and that sections examined in the tail correlate to metabolic changes, the examination of tissue from a standardized site does provide consistency of results.

Establishment of the progression of this lesion in individual monkeys followed longitudinally for years, and association of this lesion with the hormonal changes that eventually lead to the glycaemic alterations characteristic of diabetes, provide proof that this lesion precedes diabetes. Although results do not rule out deposition of amyloid secondary to diabetes, there is no evidence to support such a contention.

Islet amyloid has been found in a significant number of older humans with diabetes, although it has not been possible to establish whether the islet lesion is primary $[3,20-22]$ or secondary $[7,18,23-25]$ to the diabetes. Most diabetes in older people is generally attributable to causes other than an islet lesion, e.g. obesity, receptor defects, and other causes [26-28]. The presence of an islet lesion that causes loss or impairment of secretory cells concurrently with amyloid deposition could exacerbate diabetes arising from other causes in some people and be the sole cause for diabetes in others.

Acknowledgments. Among the many people who have contributed to this work over the last 15 years, I particularly thank Ms. J.Wolff, T. Van Bueren, L. Bonnett, and Mr. G. Clausen for their laboratory assistance; Dr. J. Palotay for help in pathology and histochemistry; and Dr. J. Hill and W. Baughman for the surgical removal of pancreatic biopsy samples. This is Publication No.1449 from the Oregon Regional Primate Research Center, supported by Animal Resources Branch Grant RR-00163 and General Research Support Grant RR-05694, both from the Division of Research Resources, National Institutes of Health. Work from this laboratory has been supported recently by U.S. Public Health Service Grants AM-21982, AG-2281, and RR05694, and by The Kroc Foundation and The Murdock Medical Trust. 


\section{References}

1. Howard CF Jr (1978) Insular amyloidosis and diabetes mellitus in Macaca nigra. Diabetes 27: 357-364

2. Opie EL (1900-01) The relation of diabetes mellitus to lesions of the pancreas. Hyaline degeneration of the islands of Langerhans. J Exp Med 5: 527-540

3. Van Beek C (1939) Amyloid deposits in islands of Langerhans in diabetes mellitus. Ned Tijdschr Geneeskd 83: 646-654

4. Bell ET (1952) Hyalinization of the islets of Langerhans in diabetes mellitus. Diabetes 1:341-344

5. Ludwig G, Heitner H (1967) Zur Häufigkeit der Inselamyloidose des Pankreas beim Diabetes Mellitus. Zschr Ges. Inn Med 22: 814-818

6. Yamada Y (1968) Pathologic study on amyloidosis. Amyloidosis of the islets of Langerhans in diabetes mellitus. Bull Yamaguchi Med School 15:227-250

7. Melato M, Antonutto G, Ferronato E (1977) Amyloidosis of the islets of Langerhans in relation to diabetes mellitus and aging. Beitr Pathol 160:73-81

8. Howard CF Jr (1972) Spontaneous diabetes in Macaca nigra. Diabetes 21: 1077-1090

9. Howard CF Jr, Fang T-Y (1984) Islet cell cytoplasmic antibodies in Macaca nigra. Diabetes 33:219-223

10. Howard CF Jr, Van Bueren A (1986) Changes in islet cell composition during development of diabetes in Macaca nigra. Diabetes 35: $165-171$

11. Howard CF Jr, Van Bueren A (1981) Immunoreactive glucagon in nondiabetic and diabetic Macaca nigra. Horm Metab Res 13: 203-206

12. Howard CF Jr (1982) Correlations of hemoglobin $A_{I c}$ and metabolic status in nondiabetic, borderline diabetic, and diabetic $\mathrm{Ma}$ caca nigra. Diabetes 31: 1105-1108

13. Howard CF Jr (1979) Aortic atherosclerosis in normal and spontaneously diabetic Macaca nigra. Atherosclerosis 33:479-493

14. Baughman WL, Howard CF Jr, Hill JD (1982) A new method of longterm/serial pedicle pancreas biopsy in rhesus macaques ( $\mathrm{Ma}$ caca mulatta) and celebes black macaques (Macaca nigra). Lab Anim Sci 32: 439

15. Brunzell JD, Robertson RP, Lerner RL, Hazzard WR, Ensinck JW, Bierman EL, Porte D Jr (1976) Relationships between fasting plasma glucose levels and insulin secretion during intravenous glucose tolerance. J Clin Endocrinol Metab 42: 222-229
16. National Diabetes Group (1979) Classification and diagnosis of diabetes mellitus and other categories of glucose. Diabetes 28: 1039-1057

17. Mallory FB (ed) (1914) The principles of pathogenic histology. Saunders, Philadelphia, pp 519-530

18. Westermark P (1972) Quantitative studies of amyloid in the islets of Langerhans. Ups J Med Sci 77: 91-94

19. Clark A, Holman RR, Matthews DR, Hockaday TDR, Tumer RC (1984) Non-uniform distribution of islet amyloid in the pancreas of 'maturity-onset' diabetic patients. Diabetologia $27: 527-528$

20. Cecil RL (1914) Hyaline degeneration of the islands of Langerhans in non-diabetic conditions. Am J Med Sci 147: 726-735

21. Arey JB (1943) Nature of the hyaline changes in islands of Langerhans in diabetes mellitus. Arch Pathol 36:32-38

22. Schneider H-M, Storkel S, Will W (1980) Das Amyloid der Langerhansschen Inseln und seine Beziehung zum Diabetes Mellitus. Dtsch Med Wochenschr 105: 1143-1147

23. Westermark P, Grimelius L (1973) The pancreatic islet cells in insular amyloidosis in human diabetic and non-diabetic adults. Acta Pathol Microbiol Immunol Scand 81: 291-300

24. Yano BL, Hayden DW, Johnson KH (1981) Feline insular amyloid: association with diabetes mellitus. Vet Pathol 18: 621-627

25. Maloy AL, Longnecker DA, Greenberg ER (1981) The relation of islet amyloid to the clinical type of diabetes. Hum Pathol 12: 917-922

26. Ganda OP, Soeldner SS (1977) Genetic, acquired and related factors in the etiology of diabetes mellitus. Arch Intern Med 137: $461-469$

27. Fajans SS (1981) Etiologic aspects of types of diabetes. Diabetes Care 4: 69-75

28. Olefsky JM (1981) Insulin resistance and insulin action. An in vitro and in vivo perspective. Diabetes $30: 149-162$

Received: 21 October 1985

and in revised form: 20 October 1986

Dr. Charles F. Howard Jr. Oregon Regional Primate Research Center 505 N. W. 185 th Avenue Beaverton, Oregon 97006 USA 